\title{
Towards a new model of grit within a cognitive-affective framework of self-regulation
}

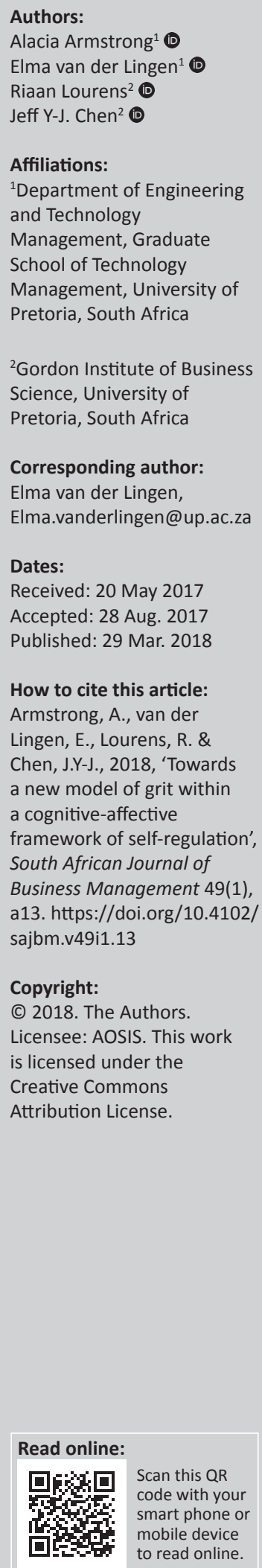

Grit - passion and perseverance for long-term goals - has been empirically shown to be a positive predictor of success across multiple contexts. The current study developed a new framework of grit within a framework of self-regulatory behaviours. Here, a qualitative approach was assumed to obtain interview data from chief innovation officers and chief information officers within technologically intensive industries. Empirical evidence was used to inductively determine the underlying cognitive-affective processing that influences gritty behaviour. Overall, six strategies were identified: temporal perspective, perpetual evaluation, motivational orientation, strength and resource gathering, system thinking and framing. Organisations may utilise the grit model developed here to enhance the grittiness of their innovation leaders by building effective cognitive-affective strategies.

\section{Introduction}

Success has been related to traits such as lateral thinking capability, risk-taking behaviour, creativity and opportunity recognition. Qualitative studies by Winner (1996) and Bloom and Sosniak (1985) confirmed the importance of motivation and perseverance as essential characteristics of successful achievers, regardless of their domain or intelligence. Grit - passion and perseverance for long-term goals - is a proven important individual characteristic for the successful attainment of goals across diverse contexts (Duckworth et al. 2007). Features of grit include the behaviours that individuals exhibit such as working tirelessly to surpass challenges, maintaining prolonged interest, passion and effort, while overcoming adversity and failures (Duckworth et al. 2007). Complementing prior research on how innovation leaders succeed under adverse circumstances (Holland \& Shepherd 2013; Mueller, Wolfe \& Syed 2017), our research underscores the importance of self-regulatory strategies in enhancing grit.

The question of why some individuals are more successful than others has been the subject of extant research in the management and entrepreneurship literature (Bandura 1977; Baum \& Locke 2004; Dyer, Gregersen \& Christensen 2008). The importance of grit-related constructs as individual traits for success has been studied as passion and tenacity (Baum \& Locke 2004); creativity, selfefficacy and goal-setting (Baum 2015); persistence (Holland \& Shepherd 2013); resilience (Kossek \& Perrigino 2016; Shin, Taylor \& Seo 2012); and self-regulatory processes (Locke \& Latham 2013; Mueller et al. 2017; Nambisan \& Baron 2013; Vallerand, Houlfort \& Forest 2014).

Grit has been studied in relation to enhanced self-discipline (Duckworth \& Kern 2011), sustained attention (DiMenichi \& Richmond 2015), self-regulated learning (Wolters \& Hussain 2015) and approaches to happiness (Von Culin, Tsukayama \& Duckworth 2014). In the context of goaldirected behaviour, both grit and self-regulation highlight the importance of regulating behaviour under challenging circumstances to achieve long-term goals (Duckworth \& Gross 2014). Recently, individual variations in grit were proposed to be derived from passion, via a self-regulatory mode (Mueller et al. 2017). In addition, the positive relationship between grit and self-regulation has been shown (Duckworth \& Gross 2014). It therefore follows that the self-regulatory competence displayed by individuals may result in gritty behaviours.

In this study, a novel contribution is made by conceptualising grit within a cognitive-affective framework of self-regulation by drawing predominantly on theories from Duckworth and Gross (2014), Robertson-Kraft and Duckworth (2014) and Mischel and Ayduk (2002). We propose that innovation leaders utilise a range of self-regulatory cognitive-affective strategies that result in the necessary gritty behaviour that enables the successful attainment of their long-term goals. Here, we assumed an inductive approach to identify what strategies (if any) chief innovation officers (CInOs) and chief information officers (CIOs) utilise to succeed. 


\section{Theoretical background}

In psychology research, grit has been defined as the pursuit of long-term goals with sustained passion and effort (Duckworth et al. 2007). Duckworth et al. (2007) developed a 12-item grit scale, which was condensed into an 8-item scale (Duckworth \& Quinn 2009), separating grit into two related dimensions: consistency of interest and perseverance of effort. Constructs such as grit and its related components have been studied as predictors of long-term success under arduous circumstances in multiple contexts (Baum \& Locke 2004; Duckworth \& Gross 2014; Duckworth, Quinn \& Seligman 2009; Locke \& Latham 2013; Vallerand et al. 2014; Wolters \& Hussain 2015; Wrzesniewski 2012). Duckworth et al. (2007) proposed that grit should be differentiated from (while related to) the traditional Big Five trait of conscientiousness based on the relative importance of stamina (pursuing goals with high effort and intensity) because grit involves long-term commitment, not short-term intensity (Duckworth et al. 2009).

Grit has been suggested to be related to, but separate from, the need for achievement, which is a motivational theory dependent on the instantaneous feedback on performance (McClelland 1967). Gritty individuals stay focused on achieving their goals under circumstances that lack positive feedback (Duckworth et al. 2007). Research on grit has consistently highlighted the importance of perseverance (Bartone, Kelly \& Matthews 2013; Maddi et al. 2012; Strayhorn 2014), passion (Duckworth \& Seligman 2006; Mueller et al. 2017; RobertsonKraft \& Duckworth 2014) and self-regulation (Duckworth \& Gross 2014; Duckworth \& Seligman 2005; Moffitt et al. 2011; Wolters 2003), which are further described hereunder.

\section{Perseverance}

Originally conceptualised by Clark (1935), perseverance is a trait that enables employees to endure and overcome challenges in their organisations (Stoltz 1997). Two constructs of perseverance crucial to success have been identified perceived control over adversity and perceived responsibility to the outcome of adversity (Markman, Baron \& Balkin 2005). Eisenberger and Leonard (1980) demonstrated that an individual's course of action, the amount of effort, their sustained resilience and length of endurance are influenced by their perseverance. The importance of perseverance and related constructs (such as persistence and resilience) when facing challenges has been demonstrated in studies of selfefficacy, exhaustion of self-control resources and goal orientation (Bandura 1977; Baumeister et al. 1998). In recent years, the interest in the empirical study of perseverance as a trait predictor has been revived in positive psychology (Peterson \& Seligman 2004) and in entrepreneurial cognitive processing (Markman et al. 2005).

\section{Passion}

Passion has been categorised as a motivational construct, described as a strong proclivity towards a significant activity an individual enjoys (Vallerand 2007) and a strong inclination to engage in specific activities (Philippe et al. 2010). Motivation and passion, while related, are distinct constructs. Passion is more specifically associated with an intense, positive inclination towards a specific task (Vallerand et al. 2003), while motivation entails a range of psychological forces encouraging individuals to exert effortful behaviour (Gatewood et al. 2002). This distinction has been demonstrated empirically when comparing intrinsic and extrinsic motivation to passion (Vallerand et al. 2003) with passion influencing motivation (Vallerand 2007). Passion can therefore be considered a domain-specific motivational construct (Chen, Yao \& Kotha 2009), important in the entrepreneurship and management literature (Mueller et al. 2017). The importance of passion in the successful outcome of particular tasks has been confirmed by Baum and Locke (2004), Vallerand et al. (2014), Houlfort et al. (2015), and has recently been shown to be important in venture success (Mueller et al. 2017).

\section{Self-regulation}

Self-regulation relates to the self-control behaviour exhibited in the pursuit of goal attainment (Mischel \& Ayduk 2002) and has been referred to as self-control (Duckworth \& Gross 2014), impulse control (Metcalfe \& Mischel 1999) and delay of gratification and self-discipline (Mischel \& Underwood 1974). Here, self-regulation is the broad description of behaviours that reflect an individual's capacity to control responses in resisting temptation to achieve long-term goals (Baumeister, Vohs \& Tice 2007; Metcalfe \& Mischel 1999; Mischel \& Underwood 1974; Mischel et al. 2010). Such regulatory competence highlights the importance of control over emotions, thoughts and behaviours in order to prioritise the attainment of a long-term goal. Self-control (as a construct within the self-regulation paradigm) serves as a powerful predictor of numerous consequential outcomes, such as general intelligence and socio-economic status (Duckworth \& Seligman 2005; Moffitt et al. 2011). Interventions aimed at enhancing self-regulation techniques such as mindfulness, problem-solving methods and employed cognitive behavioural training have proven to successfully enhance self-regulatory capacity (Piquero, Jennings \& Farrington 2010). Self-regulatory processes have been researched in entrepreneurship and innovation literature (Baron \& Henry 2010; Mitchell et al. 2007).

\section{Grit within a self-regulatory framework}

The cognitive-affective personality system (CAPS) has been well-studied as a framework for understanding selfregulation and underscores the importance of contextual stimuli on cognitive-affective processing, a determinant of behaviour (Mischel \& Ayduk 2002; Mischel \& Underwood 1974). Mischel and Ayduk (2002) further developed the CAPS paradigm demonstrating that certain cognitiveaffective strategies assisted individuals in resisting immediate gratification in pursuit of temporally distant goals. For example, the ability to alter the mental 
representation of a current temptation or redirecting attentional focus (cognitive reappraisal) is an effective strategy within the delay gratification paradigm. Research has demonstrated that individuals are able to control levels of motivation, representing motivational regulation strategies (Wolters 2003). Such strategies are thought to be principally important when individuals are facing impediments to their continued engagement and effort in certain tasks (Wolters 1998, 2003). In line with this, and recent studies (Datu 2017; Hill et al. 2016; Mueller et al. 2017; Vela et al. 2015), we conceptualise grit as a malleable construct, as opposed to a static personality trait. We propose that grit should be conceptualised within a cognitive-affective framework of self-regulation in order to identify and understand grit-enhancing strategies.

The central interest of this article, and in response to the fractionated studies on grit and self-regulation, is an integrative framework for understanding grit within a cognitive-affective framework of self-regulation.

\section{Research methodology Population and sample}

This study delineates the qualitative insights obtained from CIOs and CInOs, as innovation leaders in South Africa. The population selected for this research comprised senior managers with positions as CIOs and CInOs, for at least 2 years, from private companies in Johannesburg, South Africa. Chief information officers and CInOs are essential to innovation and need to innovate under increasingly challenging circumstances. In addition, this is the first study on grit in South Africa, despite its diverse range of challenges, and the economic importance of CIOs and CInOs. Such executives need to innovate rapidly in a challenging environment and solve dynamic challenges as they arise and are consequently an ideal population to investigate the potential strategies used to exhibit gritty behaviour.

\section{Demographic analysis of participants}

The semi-structured interviews were conducted with 40 participants across 10 industries (Table 1). The majority of the predominantly male $(90 \%)$ respondents were in the finance and insurance industry. Overall, 27 CIOs and 13 CInOs were

TABLE 1: Number of participants interviewed per industry.

\begin{tabular}{lc}
\hline Industries & Number of participants \\
\hline Finance and insurance & 18 \\
ICT and electronics & 7 \\
Logistics & 5 \\
Engineering & 3 \\
Legal & 2 \\
FMCG & 1 \\
Education & 1 \\
Health & 1 \\
Manufacturing & 1 \\
Media & 1 \\
\hline
\end{tabular}

ICT, information and communication technology; FMCG, fast-moving customer goods. interviewed. Participants were involved in at least one project that encompassed technological and innovative components pursued over a period of at least 2 years to satisfy the longterm construct of grit.

\section{Research design and data collection}

A qualitative interpretation was followed to unpack the insights obtained from the semi-structured, face-to-face interviews. This process permits the interviewees to freely propose their own perspectives without being influenced by the perceptions of the interviewer (Johnson \& Harris 2002) and enables a deeper understanding of relevant concepts. In addition, qualitative approaches are preferred to quantitative approaches when the concept is complex, ambiguous or lacks existing knowledge (Blumberg, Cooper \& Schindler 2014) and is therefore better suited to explore grit as a behavioural trait within a cognitive-affective framework. Grit was described to the interviewees as a set of behaviours that enable individuals to pursue long-term goals under challenging conditions and multiple setbacks.

The initial interview questions were the following:

- In order to overcome challenging situations in your workplace environment, what thinking processes do you use that enable you to exhibit gritty behaviour?

- How does your organisation help you to achieve this?

- Please provide a reason for your answer(s).

These questions were designed to engage the interviewees without bias and allow them to express their own perspectives on grit. Subsequent questions were directed to discern the participants' meaning associated with specific responses and elicit descriptions regarding (1) how the individual makes decisions, (2) his or her attitude towards team members and the organisation, and (3) how he or she perseveres and remains motivated. Questions included, 'How would you define grit?', 'From your work experience thus far, how do you overcome failure in challenging projects?', 'Under what circumstances is failure acceptable?' and 'How do you stay motivated?'

\section{Data analysis and interpretation}

The interpretive phenomenological analysis (IPA) method of data analysis was used and involved the collection of verbal data from a knowledgeable source for the purpose of gathering insight and unpacking constructs relevant to the research questions (Smith 1996). A simple interpretative approach of thematic analysis was undertaken by identifying keywords that designate the principle underlying constructs of the interviewees. Thematic analysis is a process of analysing a data set and identifying repeated patterns of meaning, that is, themes (Aronson 1995; Braun \& Clarke 2006). Transcripts were created from each interview and studied intensely to identify common themes that reflected the interviewees' perspectives on grit and strategies. 
Relevant data were identified across the data sets, consisting of listed patterns of experience and features of interest (codes) from the transcribed data (Aronson 1995; Braun \& Clarke 2006), where codes are raw data that are interpreted in a meaningful way. Consequently, the codes and patterns that emerged were grouped into sub-themes that highlighted linked patterns of experience and meaning (Braun \& Clarke 2006). Sub-themes were combined and integrated into themes (Aronson 1995). Thematic relationships between different respondents were explored in a systematic and continuous reflective researcher dialogue (Braun \& Clarke 2006). Themes were extracted from the data and similar themes were named and grouped together to create higher order themes, as indicated in Figure 1. Once identified, themes were analysed for coherence and identifiable discrepancies across the entire data set (Aronson 1995).

\section{Thematic results}

Three higher order themes, with 12 categories, emerged through thematic analysis of the data set. The higher order themes were related to the following dominant strategies: (1) assumption of the appropriate temporal perspective and perpetual self-evaluation by the individual, (2) intervention between the individual and challenges and (3) the relationship between the individual and the ecosystem. The thematic process revealed that emergent themes paralleled several theories in psychology and entrepreneurship research. Each theme and associated category will be delineated in more detail below.

\section{Individual (temporal orientation and perpetual evaluation)}

The first category of cognitive-affective strategies that emerged was temporal perspective $(20 \%$ of respondents; Figure 2). The awareness of their strong personal identity was linked to a goal-oriented future perspective. In the next category, participants subjected themselves to perpetual evaluation through displaying either self-dissatisfaction or satisfaction (35\% of respondents). We found that participants motivated themselves through constant feedback from their progress, whether positive or negative. Under circumstances where individuals realised that their current actions were not meeting their desired future goals, they were able to adjust their behaviour accordingly in order to move closer to desired future states.

\section{Individual and challenges (system thinking and framing)}

As a prevalent pattern of behaviour, we observed that $40 \%$ of the participants used a system thinking approach when dealing with challenges (Figure 2). Participants applied system thinking by either identifying and solving sub-goals or addressing the challenge in its entirety. System thinking was associated with the fourth category of framing, which related to participants' orientation to failure. Failure was used as a motivator to identify new avenues for growth by $57.5 \%$ of the participants.

\section{Individual and ecosystem (strength and resource gathering and motivational orientation)}

The fifth category is related to the relationship of the individuals to their environment (including their team, organisation and external networks), which they leveraged to achieve goals. Sixty-five per cent of the interviewees suggested that their teams or broader ecosystems often complemented their personal weaknesses, as indicated in Figure 2. The final category was associated with the motivational orientation of participants, with participants motivated to succeed beyond personal gains, instead of focusing on the potential benefits to their ecosystem (40\% of participants).

\section{Discussion}

Data analysis resulted in three higher-order themes (Individual; Individual and Challenges; Individual and Ecosystem), each consisting of two paradoxical strategies used by CIOs and CInOs. The six paradoxical strategies identified were temporal perspective, perpetual evaluation, motivational orientation, strength and resource gathering, system thinking and framing, as shown in Figure 3. The proposed model of grit provides a framework for potentially enhancing the grit of innovation leaders by employing the six strategies.

Results revealed that the participants showed a strong understanding of their current strengths and weaknesses (present-self) in addition to focusing on their future goals (future-self). A preference towards a certain time (past, present or future) has been shown to significantly influence decision-making, ultimately influencing behaviour (Destin \& Oyserman 2009; Nuttin 2014). It therefore follows that individuals who are more future-oriented may be able to better restrain themselves from impulsive decisions that may negatively impact important long-term goals as they have a clear connection between present and future. It has been shown that people will act in the interest of their future-self if they can visualise the two selves as connected and not conflicted (Lewis \& Oyserman 2015). Therefore, effectively visualising the desired future scenario and the benefits that could be obtained as a result, assuming that intensity and duration of effort is adjusted accordingly, is an important grit-enhancing strategy.

Another key finding is that individuals had two perspectives on perpetual evaluation: constant dissatisfaction and satisfaction. Accordingly, participants used both perspectives to motivate themselves through challenging circumstances. While Bandura and Cervone (1983) proposed selfdissatisfaction theory to explain the comparative cognitiveaffective processes individuals use to motivate themselves in long-term goal attainment, the presence of both these perspectives as a source of self-directed motivation has not, to our knowledge, been shown previously.

Participants who employed the systems thinking strategy favoured the adoption of a simpler sub-goal as opposed to attempting to overcome the obstacle in its entirety. 


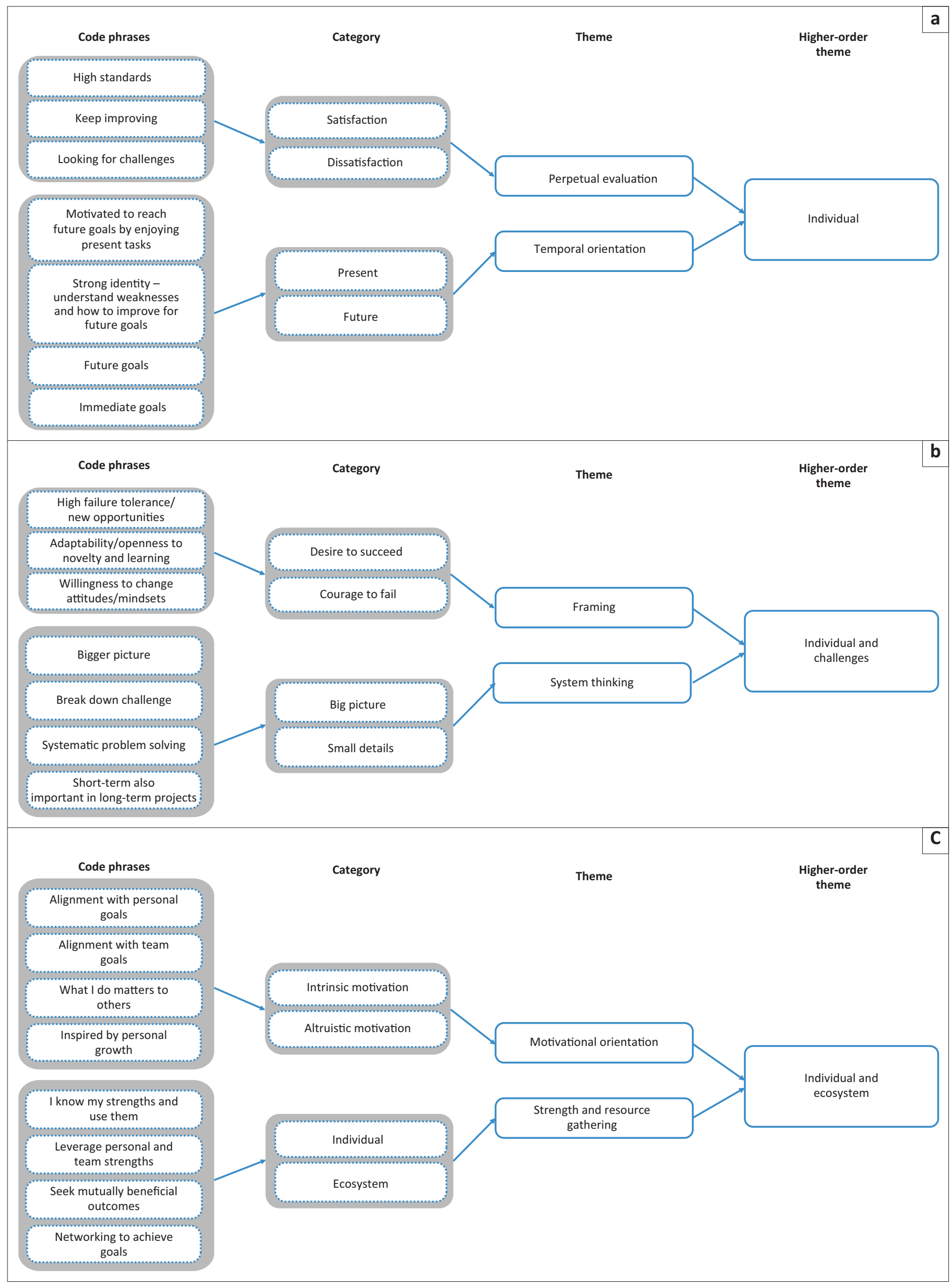

FIGURE 1: Examples of thematic analysis of interview data related to the higher-order theme (a) 'Individual'; (b) 'Individual and Challenges'; and (c) 'Individual and Ecosystem'. 


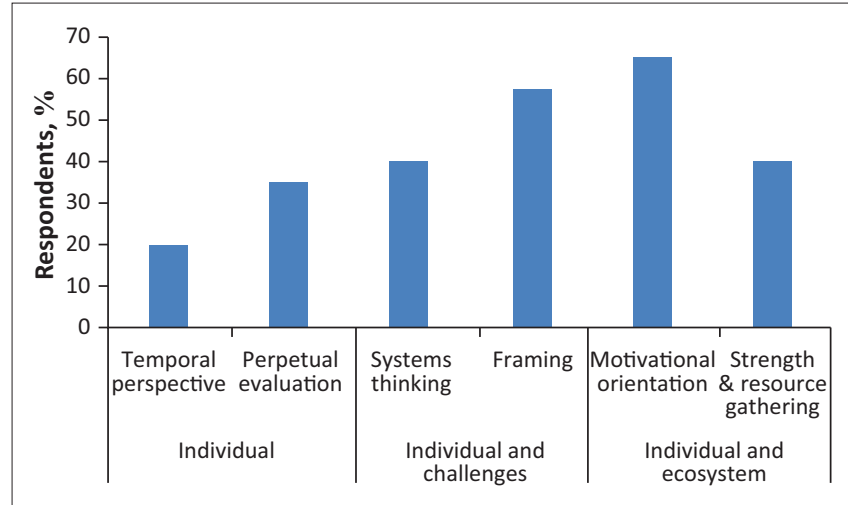

FIGURE 2: Frequency of participant responses related to each indentified strategy

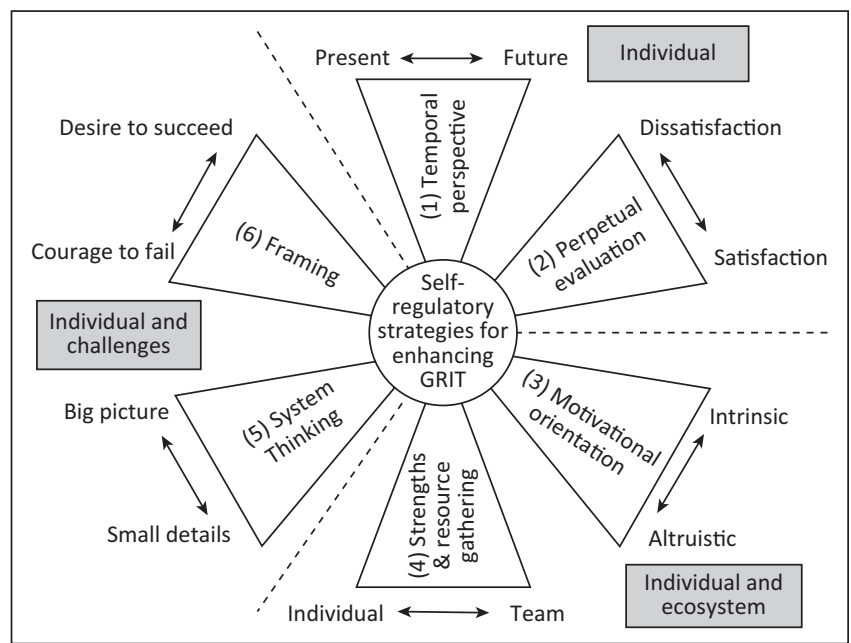

FIGURE 3: New model of grit delineated from thematic analysis of interviews depicting six self-regulatory strategies for enhancing grit.

This helps mitigate discouragement when faced with difficult challenges. According to our observations, the celebration of achieving smaller sub-goals assisted with participants maintaining the pursuit of long-term goals. Adopting a system thinking approach has been considered one of the key attributes of successful leaders (Jenkins Johnson 1997). The ability to visualise a problem's 'full picture', in terms of all the relevant interlinked aspects and how the problem may unfold over time, is an important skill for innovation leaders (Liedtka 2000).

Results underscored the importance that a particular perspective that an individual assumed regarding failure determined their behaviour towards challenging circumstances. For example, some participants believed failure to be an unforeseen opportunity and therefore a new avenue for growth. Similar behaviours have been observed with entrepreneurs using the effectual process (alteration or adaptation of goals in accordance with the situational context). Such individuals are more equipped to succeed in environments with great uncertainty (Perry, Chandler \& Markova 2012; Sarasvathy 2001), leveraging unforeseen circumstances to work in their favour. Recently, DiMenichi and Richmond (2015) revealed that focusing on past failures resulted in increased perseverance and sustained attention in comparison to reflecting on past successes. It appears that gritty individuals reframe negative past experiences into a more constructive outcome for future success in comparison to their less gritty counterparts.

Participants revealed a strong desire to succeed stimulated by the belief that they have the capabilities to succeed. Observations pointed to the use of individual strengths and ecosystem strengths to improve the likelihood of the project success, and the leveraging networks to address remaining weaknesses. Establishing and maintaining a good ecosystem therefore becomes a potentially powerful intervention strategy to assist employees to remain gritty in adverse circumstances. Such an ecosystem of social support enables individuals to leverage resources more effectively, alleviating stress and mitigating potential resource losses. Strength-based theory focuses on identifying and building strengths in order to overcome challenges (Bouskila-Yam \& Kluger 2011; Buckingham \& Clifton 2001). Employees may therefore exhibit higher performance when they leverage their strengths (Buckingham 2010).

Results indicated the importance of intrinsic and altruistic forms of motivation, seeking both meaning and pleasure within their work. Similarly to Von Culin et al. (2014), we found altruism to be an important aspect of grit, and that gritty individuals have a high sense of altruism providing meaning in their work, motivating them to work harder with sustained interest for longer periods of time. Altruistic behaviour in combination with intrinsic motivation better predicts performance, perseverance and productivity (Grant 2008).

\section{Practical value}

The research presented here elucidated the importance of understanding the strategies used to address challenges in pursing long-term goals, and that these strategies impact the perseverance and motivation of innovation leaders. It is therefore imperative to understand such leaders' perspectives and current strategies of undertaking complex tasks. Although failures result from the high level of risk required to maintain competitive advantage, organisations remain biased against failure. The lack of learning from failure and exploiting it as an unforeseen advantage makes it difficult to innovate as necessary. 'System thinking' had the lowest frequency of responses, highlighting the importance of working on this cognitive-affective strategy to improve gritty behaviour. In addition, the importance of leveraging networks and organisational ecosystem were highlighted. Organisations can use the insights gained here to improve grit-enhancing strategies of innovative leaders.

\section{Limitations and future work}

This study has a number of limitations that should be taken into account with respect to the model produced from our results. Firstly, qualitative studies have a number of inherent limitations which include the self-report nature of the measures used. While we have attempted to mitigate this 
through comprehensive thematic analysis with oversight from the authors, future work should test this model quantitatively in a variety of different contexts. Secondly, we did not measure the individual success of participants and based this solely on the interviewees' accounts of success and their current status in their company.

This work focused on CInOs and CIOs in South Africa and only $10 \%$ of interviewees were female, limiting the generalisation capability of the research outcomes. Qualitative methods enable the interviewer to derive a number of plausible insights based on the participants' responses and are highly suited to investigate novel or understudied subjects. Such methods, however, are limited in quantifying the relative importance of specific components in relation to the overall construct of interest (grit). The preliminary model developed here could be subjected to future quantitative enquiry in a variety of fields to enhance the reproducibility, validity and transferability of the findings.

\section{Conclusion}

The purpose of this study was to explore what grit-enhancing strategies South African innovation leaders currently employ to remain successful in a challenging innovation environment. Through the qualitative extrapolation of relevant themes, a preliminary grit model was developed. The findings identified the existence of three higher-order themes, that is, individual, individual and challenges, and individual and ecosystem, containing six paradoxical gritenhancing strategies. This novel conceptualisation of gritenhancing paradoxical strategies may enable organisations to assist their employees to examine and reflect on their own thought-processing in pursuit of personal and professional goal attainment. The insights gained from this study may add to the existing literature on grit, mindsets and decisionmaking. While our interviews revealed constructs of grit previously identified (perseverance, motivation and selfregulation), this study has gained several new insights. In addition to the new model of grit developed, this study examined the underlying processes that result in gritty behaviour, as opposed to quantitatively correlating grit with measures of success. Possible strategies have been identified that may be implemented to enhance innovation leaders' grit in organisations.

\section{Acknowledgements}

The authors would like to thank the Graduate School of Technology Management and the Gordon Institute of Business Science, University of Pretoria, for permission to publish the results.

\section{Competing interests}

The authors declare that they have no financial or personal relationships which may have inappropriately influenced them in writing this article.

\section{Authors' contributions}

A.A. did the literature survey, and A.A., E.v.d.L. and J.Y-J.C. analysed and interpreted data, and J.Y-J.C. conceptualised the grit model. A.A. and E.v.d.L. were involved in the writing of the article. R.L. was involved in data collection.

\section{References}

Aronson, J., 1995, 'A pragmatic view of thematic analysis', The Qualitative Report 2, $1-3$

Bandura, A., 1977, 'Self-efficacy: Toward a unifying theory of behavioral change', Psychological Review 84, 191. https://doi.org/10.1037/0033-295X.84.2.191

Bandura, A. \& Cervone, D., 1983, 'Self-evaluative and self-efficacy mechanisms governing the motivational effects of goal systems', Journal of Personality and Social Psychology 45, 1017. https://doi.org/10.1037/0022-3514.45.5.1017

Baron, R.A. \& Henry, R.A., 2010, 'How entrepreneurs acquire the capacity to excel: Insights from research on expert performance', Strategic Entrepreneurship Journal 4, 49-65. https://doi.org/10.1002/sej.82

Bartone, P.T., Kelly, D.R. \& Matthews, M.D., 2013, 'Psychological hardiness predicts adaptability in military leaders: A prospective study', International Journal of Selection and Assessment 21, 200-210. https://doi.org/10.1111/ijsa.12029

Baum, J.R., 2015, ‘Gain entrepreneurship success through swiftness and experimentation', Handbook of Principles of Organizational Behavior, 559-580.

Baum, J.R. \& Locke, E.A., 2004, 'The relationship of entrepreneurial traits, skill, and motivation to subsequent venture growth', Journal of Applied Psychology 89, 587. https://doi.org/10.1037/0021-9010.89.4.587

Baumeister, R.F., Bratslavsky, E., Muraven, M. \& Tice, D.M., 1998, 'Ego depletion: Is the active self a limited resource?', Journal of Personality and Social Psychology 74 1252. https://doi.org/10.1037/0022-3514.74.5.1252

Baumeister, R.F., Vohs, K.D. \& Tice, D.M., 2007, 'The strength model of self-control', Current Directions in Psychological Science 16, 351-355. https://doi.org/10.1111/ j.1467-8721.2007.00534.x

Bloom, B.S. \& Sosniak, L.A., 1985, Developing talent in young people, Ballantine Books, New York.

Blumberg, B.F., Cooper, D.R. \& Schindler, P.S., 2014, Business research methods, McGraw-Hill Education, New York.

Bouskila-Yam, O. \& Kluger, A.N., 2011, 'Strength-based performance appraisal and goal setting', Human Resource Management Review 21, 137-147. https://doi. org/10.1016/j.hrmr.2010.09.001

Braun, V. \& Clarke, V., 2006, 'Using thematic analysis in psychology', Qualitative Research in Psychology 3, 77-101. https://doi.org/10.1191/1478088706qp063oa

Buckingham, M., 2010, Go put your strengths to work: 6 powerful steps to achieve outstanding performance, Simon and Schuster, New York.

Buckingham, M. \& Clifton, D.O., 2001, Now, discover your strengths, Simon and Schuster, New York.

Chen, X.-P., Yao, X. \& Kotha, S., 2009, 'Entrepreneur passion and preparedness in business plan presentations: A persuasion analysis of venture capitalists' funding decisions', Academy of Management Journal 52, 199-214. https://doi. org/10.5465/AMJ.2009.36462018

Clark, W.H., 1935, 'Two tests for perseverance', Journal of Educational Psychology 26, 604. https://doi.org/10.1037/h0053523

Datu, J. A. D., 2017, 'Sense of relatedness is linked to higher grit in a collectivist setting', Personality and Individual Differences 105, 135-138.

Destin, M. \& Oyserman, D., 2009, 'From assets to school outcomes: How finances shape children's perceived possibilities and intentions', Psychological Science 20, 414-418. https://doi.org/10.1111/j.1467-9280.2009.02309.x

Dimenichi, B.C. \& Richmond, L.L., 2015, 'Reflecting on past failures leads to increased perseverance and sustained attention', Journal of Cognitive Psychology 27, 180193. https://doi.org/10.1080/20445911.2014.995104

Duckworth, A. \& Gross, J.J., 2014, 'Self-control and grit: Related but separable determinants of success', Current Directions in Psychological Science 23, 319-325. https://doi.org/10.1177/0963721414541462

Duckworth, A.L. \& Kern, M.L., 2011, 'A meta-analysis of the convergent validity of selfcontrol measures', Journal of Research in Personality 45, 259-268. https://doi. org/10.1016/j.jrp.2011.02.004

Duckworth, A.L., Peterson, C., Matthews, M.D. \& Kelly, D.R., 2007, 'Grit: Perseverance and passion for long-term goals', Journal of Personality and Social Psychology 92 1087. https://doi.org/10.1037/0022-3514.92.6.1087

Duckworth, A.L. \& Quinn, P.D., 2009, 'Development and validation of the Short Grit Scale (GRIT-S)', Journal of Personality Assessment 91, 166-174. https://doi. org/10.1080/00223890802634290

Duckworth, A.L., Quinn, P.D. \& Seligman, M.E., 2009, 'Positive predictors of teacher effectiveness', The Journal of Positive Psychology 4, 540-547. https://doi. org/10.1080/17439760903157232

Duckworth, A.L. \& Seligman, M.E., 2005, 'Self-discipline outdoes IQ in predicting academic performance of adolescents', Psychological Science 16, 939-944. https://doi.org/10.1111/j.1467-9280.2005.01641.x 
Duckworth, A.L. \& Seligman, M.E., 2006, 'Self-discipline gives girls the edge: Gender in self-discipline, grades, and achievement test scores', Journal of Educational self-discipline, grades, and achievement test scores', Journal
Psychology 98, 198. https://doi.org/10.1037/0022-0663.98.1.198

Dyer, J.H., Gregersen, H.B. \& Christensen, C., 2008, 'Entrepreneur behaviors, opportunity recognition, and the origins of innovative ventures', Strategic Entrepreneurship Journal 2, 317-338. https://doi.org/10.1002/sej.59

Eisenberger, R. \& Leonard, J.M., 1980, 'Effects of conceptual task difficulty on generalized persistence', The American Journal of Psychology 1, 285-298. https:// doi.org/10.2307/1422233

Gatewood, E.J., Shaver, K.G., Powers, J.B. \& Gartner, W.B., 2002, 'Entrepreneurial expectancy, task effort, and performance', Entrepreneurship Theory and Practice 27, 187-206. https://doi.org/10.1111/1540-8520.00006

Grant, A.M., 2008, 'The significance of task significance: Job performance effects, relational mechanisms, and boundary conditions', Journal of Applied Psychology 93, 108. https://doi.org/10.1037/0021-9010.93.1.108

Hill, P. L., Burrow, A. L., \& Bronk, K. C., 2016, 'Persevering with positivity and purpose: An examination of purpose commitment and positive affect as predictors of grit.' An examination of purpose commitment and

Holland, D.V. \& Shepherd, D.A., 2013, 'Deciding to persist: Adversity, values, and entrepreneurs' decision policies', Entrepreneurship Theory and Practice 37, 331358. https://doi.org/10.1111/j.1540-6520.2011.00468.x

Houlfort, N., Fernet, C., Vallerand, R.J., Laframboise, A., Guay, F. \& Koestner, R., 2015, 'The role of passion for work and need satisfaction in psychological adjustment to retirement', Journal of Vocational Behavior 88, 84-94. https://doi.org/10.1016/j. jvb.2015.02.005

Jenkins Johnson, M., 1997, 'Entrepreneurial intentions and outcomes: A comparative causal mapping study', Journal of Management Studies 34(6), 895-920. https:// doi.org/10.1111/1467-6486.00077

Johnson, P. \& Harris, D., 2002, 'Qualitative and quantitative issues in research design', in D. Partington (ed.), Essential Skills for Management Research, pp. 99-116, Sage, London.

Kossek, E.E. \& Perrigino, M.B., 2016, 'Resilience: A review using a grounded integrated occupational approach', Academy of Management Annals 10, 729-797.

Lewis, N.A., Jr. \& Oyserman, D., 2015, 'When does the future begin? Time metrics matter, connecting present and future selves', Psychological Science 26, 816-825. https://doi.org/10.1177/0956797615572231

Liedtka, J., 2000, 'Strategic planning as a contributor to strategic change: A generative model', European Management Journal 18(2), 195-206. https://doi.org/10.1016/ S0263-2373(99)00091-2

Locke, E.A. \& Latham, G.P., 2013, New developments in goal setting and task performance, Routledge, London.

Maddi, S.R., Matthews, M.D., Kelly, D.R., Villarreal, B. \& White, M., 2012, 'The role of hardiness and grit in predicting performance and retention of USMA cadets', Military Psychology 24, 19. https://doi.org/10.1080/08995605.2012.639672

Markman, G.D., Baron, R.A. \& Balkin, D.B., 2005, 'Are perseverance and self-efficacy costless? Assessing entrepreneurs' regretful thinking', Journal of Organizational Behavior 26, 1-19. https://doi.org/10.1002/job.305

Mcclelland, D.C., 1967, Achieving society, Simon and Schuster, New York.

Metcalfe, J. \& Mischel, W., 1999, 'A hot/cool-system analysis of delay of gratification: Dynamics of willpower', Psychological Review 106, 3. https://doi.org/10.1037/ 0033-295X.106.1.3

Mischel, W. \& Ayduk, O., 2002, 'Self-regulation in a cognitive - Affective personality system: Attentional control in the service of the self', Self and Identity 1, 113-120. https://doi.org/10.1080/152988602317319285

Mischel, W., Ayduk, O., Berman, M.G., Casey, B., Gotlib, I.H., Jonides, J. et al., 2010 '"Willpower"over the life span: Decomposing self-regulation', Social Cognitive and Affective Neuroscience 6, 252-256. https://doi.org/10.1093/scan/nsq081

Mischel, W. \& Underwood, B., 1974, 'Instrumental ideation in delay of gratification', Child Development 1, 1083-1088. https://doi.org/10.2307/1128098

Mitchell, R.K., Busenitz, L.W., Bird, B., Marie Gaglio, C., Mcmullen, J.S., Morse, E.A et al., 2007, 'The central question in entrepreneurial cognition research 2007 ' Entrepreneurship Theory and Practice 31, 1-27. https://doi.org/10.1111/j. 1540-6520.2007.00161.x

Moffitt, T.E., Arseneault, L., Belsky, D., Dickson, N., Hancox, R.J., Harrington, H. et al., 2011, 'A gradient of childhood self-control predicts health, wealth, and public safety', Proceedings of the National Academy of Sciences 108, 2693-2698. https:// doi.org/10.1073/pnas.1010076108

Mueller, B.A., Wolfe, M.T. \& Syed, I., 2017, 'Passion and grit: An exploration of the pathways leading to venture success', Journal of Business Venturing 32, 260-279. https://doi.org/10.1016/j.jbusvent.2017.02.001
Nambisan, S. \& Baron, R.A., 2013, 'Entrepreneurship in innovation ecosystems: Entrepreneurs' self-regulatory processes and their implications for new venture success', Entrepreneurship Theory and Practice 37, 1071-1097. https://doi. success', Entrepreneurship Theory and
org/10.1111/j.1540-6520.2012.00519.x

Nuttin, J., 2014, Future time perspective and motivation: Theory and research method, Psychology Press, London.

Perry, J.T., Chandler, G.N. \& Markova, G., 2012, 'Entrepreneurial effectuation: A review and suggestions for future research', Entrepreneurship Theory and Practice 36, 837-861. https://doi.org/10.1111/j.1540-6520.2010.00435.x

Peterson, C. \& Seligman, M.E., 2004, Character strengths and virtues: $A$ handbook and classification, Oxford University Press, Oxford.

Philippe, F.L., Vallerand, R.J., Houlfort, N., Lavigne, G.L. \& Donahue, E.G., 2010, 'Passion for an activity and quality of interpersonal relationships: The mediating role of emotions', Journal of Personality and Social Psychology 98, 917. https:// doi.org/10.1037/a0018017

Piquero, A.R., Jennings, W.G. \& Farrington, D.P., 2010, 'On the malleability of selfcontrol: Theoretical and policy implications regarding a general theory of crime', Justice Quarterly 27, 803-834. https://doi.org/10.1080/0741882 0903379628

Robertson-Kraft, C. \& Duckworth, A.L., 2014, 'True grit: Trait-level perseverance and passion for long-term goals predicts effectiveness and retention among novice teachers', Teachers College Record (1970), 116-140.

Sarasvathy, S.D., 2001, 'Causation and effectuation: Toward a theoretical shift from economic inevitability to entrepreneurial contingency', Academy of Management Review 26, 243-263.

Shin, J., Taylor, M.S. \& Seo, M.-G., 2012, 'Resources for change: The relationships of organizational inducements and psychological resilience to employees' attitudes and behaviors toward organizational change', Academy of Management Journal 55, 727-748. https://doi.org/10.5465/amj.2010.0325

Smith, J.A., 1996, 'Beyond the divide between cognition and discourse: Using interpretative phenomenological analysis in health psychology', Psychology and Health 11, 261-271. https://doi.org/10.1080/08870449608400256

Stoltz, P.G., 1997, Adversity quotient: Turning obstacles into opportunities, John Wiley \& Sons, New York.

Strayhorn, T.L., 2014, 'What role does grit play in the academic success of black male collegians at predominantly white institutions?', Journal of African American Studies 18, 1-10. https://doi.org/10.1007/s12111-012-9243-0

Vallerand, R.J., 2007, 'A hierarchical model of intrinsic and extrinsic motivation for sport and physical activity', in M.S. Hagger \& N.L.D. Chatzisarantis (Eds.), Intrinsic motivation and self-determination in exercise and sport, pp. 255-279, 356-363, Human Kinetics, Champaign, IL.

Vallerand, R.J., Blanchard, C., Mageau, G.A., Koestner, R., Ratelle, C., Léonard, M. et al., 2003, 'Les passions de l'ame: On obsessive and harmonious passion', Journa of Personality and Social Psychology 85, 756. https://doi.org/10.1037/00223514.85.4.756

Vallerand, R.J., Houlfort, N. \& Forest, J., 2014, 'Passion for work: Determinants and outcomes', in Gagne, M. (ed.), Oxford handbook of work engagement, motivation, and self-determination theory, pp. 85-105. Oxford University Press, Oxford

Vela, J. C., Lu, M. T. P., Lenz, A. S., \& Hinojosa, K., 2015, Positive psychology and familial factors as predictors of Latina/o students' psychological grit, Hispanic Journal of Behavioral Sciences 37(3), 287-303.

Von Culin, K.R., Tsukayama, E. \& Duckworth, A.L., 2014, 'Unpacking grit Motivational correlates of perseverance and passion for long-term goals', The Journal of Positive Psychology 9, 306-312. https://doi.org/10.1080/17439760. 2014.898320

Winner, E., 1996, Gifted children, Basic Books, New York.

Wolters, C.A., 1998, 'Self-regulated learning and college students' regulation of motivation', Journal of Educational Psychology 90, 224. https://doi.org/ 10.1037/0022-0663.90.2.224

Wolters, C.A., 2003, 'Regulation of motivation: Evaluating an underemphasized aspect of self-regulated learning', Educational Psychologist 38, 189-205. https://doi. org/10.1207/S15326985EP3804_1

Wolters, C.A. \& Hussain, M., 2015, 'Investigating grit and its relations with college students' self-regulated learning and academic achievement', Metacognition and Learning 10, 293-311. https://doi.org/10.1007/s11409-014-9128-9

Wrzesniewski, A., 2012, 'Callings', in K.S. Cameron \& G.M. Spreitzer (Eds.), The Oxford handbook of positive organizational scholarship, pp. 45-55, Oxford University Press, Oxford. 